FIRE HISTORY IN THE BIGHORN CANYON NATIONAL RECREATION AREA

\author{
Dennis H. Knight \\ Yegang Wu \\ Department of Botany \\ University of Wyoming \\ Laramie
}

\title{
Objectives
}

Research was initiated in May, 1988, to determine fire history in the coniferous forests and adjacent foothill vegetation located on East Pryor Mountain in the Bighorn Canyon National Recreation Area (BCNRA). The results, anticipated in 1990, will be useful for the development of a fire management plan.

Specifically, our research is addressing the following questions:

1. What is the mean fire return interval in the coniferous forests and shrublands of the study area?

2. How does the mean fire free interval change with differences in vegetation type, elevation, and topographic position?

3. What is the current flammability (fuel load) of the different vegetation types found in the study area, and what is the probability of fire spreading from one type to another?

4. Are spruce budworin or mountain pine beetles contributing to forest flammability?

5. What is the relative importance of grazing, topography, and fuel accumulation in determining flammability?

\section{Progress to Date}

Field work was initiated on May 24, 1988, and continued through August 7. Using orthophotoquads, the study area was divided into a grid with 800 contiguous units. Each grid unit is 4 hectares and served as a focal point for data collection. During the summer, 460 of the 800 grid units were surveyed for fire scars, fuel quantity, forest age, and vegetation type. Elevation, slope and topographic position of each grid unit were recorded also. Fuel biomass was sampled using standard methodology developed by the U.S. Forest Service, with data being recorded separately for 1-hour, 10-hour, and 100-hour fuels. Fuel samples were collected for determining the range of fuel moisture conditions experienced during 1988. Fire scars were found in 23 grid 
units.

Currently we are (1) calculating fuel moisture contents for the samples collected in 1988; (2) summarizing the fuel biomass data by location and vegetation type; (3) mapping and aging all fires detected in 1988; and (4) determining the utility of BEHAVE, a fire behavior model for predicting flammability and fire spread. This work will continue during the winter.

Field work will resume in the summer of 1989, with the goal being to finish sampling the 800 4-ha grid units of the study area. Data collection will focus on woodlands, shrublands, and grasslands, as most of the grid units in forest have been sampled.

To facilitate coordination of the BCNRA fire management plan with other agencies, initial contacts were made with the U.S. Forest Service (Custer National Forest, Red Lodge, Montana) and the Bureau of Land Management (Billings, Montana). These agencies administer land adjacent to our study area in the BCNRA. Fire history information and fire management guidelines that may exist on these BLM and USFS lands will be incorporated into the report and recommendations developed for the BCNRA. 